\title{
Changes in the Compound and Bioactivity of Suaeda japonica Makino Extract by Different Harvesting Time
}

\author{
Ji-Hye Choi*, Sung-Gyu Lee ${ }^{* *}$ and Hyun Kang ${ }^{\dagger ; * *}$ \\ Department of Medical Laboratory Science, College of Health Science, \\ Dankook University, Cheonan-si, Chungnam 31116, Korea
}

\begin{abstract}
This study was the change of compound and bioactivity were analyzed by different harvesting time (May, August, and November) of Suaeda japonica Makino. The total polyphenol and flavonoid contents of S. japonica were the highest at about $22.81 \mathrm{mg} \mathrm{GAE} / \mathrm{g}$ and $4.56 \mathrm{mg} \mathrm{QE} / \mathrm{g}$, respectively, in the $S$. japonica harvested in Nov. Also, the contents of quercetin, showed the highest content in Nov harvested $S$. japonica. In addition, the antioxidative activity of each extract from $S$. japonica changed depending on harvesting time. For $S$. japonica harvested in Nov showed the highest DPPH and ABTS radical scavenging activity. From the NO inhibition assay, the $S$. japonica harvested in Nov had shown the highest anti-inflammatory effects. Therefore, consideration of the optimal harvesting time for S. japonica could be an important factor attributing to its natural antioxidant and anti-inflammatory properties and the optimal harvesting time was confirmed especially to be in Nov.
\end{abstract}

Key Words: Different harvesting time, Suaeda japonica Makino, Polyphenol, Anti-inflammatory, Antioxidant

Suaeda japonica Makino is a continuous annual herbaceous plant belonging to the family Chenopodiaceae and is a salt-tolerant plant capable of growing at high salt concentrations along with Salicornia and Altriplex (Larcher, 1995). It is seen abundantly on muddy seashores along the coast of Korea, Japan, Europe, and Iran (Han et al., 2003). The plant of the genus Suaeda to which this species belongs is a haophytaloplant (Jung et al., 2008), which refers to a plant naturally selectively grown in a saline environment, and is a plant with high adaptability against excessive levels of ion concentration (Greenway and Munns, 1980). The $S$. japonica is considered to be rich in secondary metabolites with high bioavailability different from other organisms because it can grow in high salt and humid regions as well as contains a large amount of natural minerals (Jung et al., 2008). Therefore, it has the potential to be utilized as a functional material. In addition, S. japonica is used as natural salt, and in herbal medicine, it is used as a medicinal material including antioxidant and antipyretic effect (Choi et al., 2009).

Recently, as consumers who natural preferences and interest in well-being have increased, many attempts have been made to develop bioactive compound contained in natural raw materials as new materials for health functional foods. Particularly, polyphenolic compounds such as phenolic acid, cinamic acid, resveratrol, lignan, tannic acid, and flavonoids are well known as functional raw materials (Lee et al., 2005). These polyphenolic compounds exhibit strong

Received: October 29, 2020 / Revised: December 14, 2020 / Accepted: December 15, 2020

*Ungraduate student, ${ }^{* *}$ Professor.

${ }^{\dagger}$ Corresponding author: Hyun Kang. Department of Medical Laboratory Science, College of Health Science, Dankook University, Cheonan-si, Chungnam 31116, Korea.

Tel: +82-10-6297-3603, Fax:+82-41-559-7934, e-mail: hkang@dankook.ac.kr

(C) The Korean Society for Biomedical Laboratory Sciences. All rights reserved.

(c) This is an Open Access article distributed under the terms of the Creative Commons Attribution Non-Commercial License (http://creativecommons.org/licenses/by-nc/3.0/) which permits unrestricted non-commercial use, distribution, and reproduction in any medium, provided the original work is properly cited. 
biological activity. Moreover, they are better alternatives to several synthetic antioxidants that have side effects (Ito et al., 1983; Kahl and Kappus, 1993). Antioxidant compounds extracted from natural raw materials exhibit protective effects in cells against reactive oxygen species (ROS). They consist of peroxynitrite, superoxide, hydroxyl radicals, peroxyl radicals, and singlet oxygen, which induce oxidative stress, and thereby cause cellular damage (Bayr, 2005). Therefore, it is important to continue to evaluate the antioxidant activity and free radical scavenging ability of natural raw materials.

There is no study yet on the compound and bioactivity of $S$. japonica according to the different harvesting time. Therefore, in this study, the contents of polyphenol, flavonoid, and quercetin were analyzed by different harvesting time (May, August, and November) of $S$. japonica from the coastal area of Suncheon, Jeollanam-do, Korea. In addition, antioxidant and anti-inflammatory effect of $S$. japonica of different harvesting time were investigated.

The S. japonica samples were harvested in the period of May, August, and November 2019 at Suncheon-si (Jeollanamdo, Korea). The $S$. japonicaa was dried, ground to a fine powder ( $\sim 20$ mesh) using a milling machine, and then extracted with $70 \%$ ethanol three times by stirring for $24 \mathrm{~h}$ at RT. After filtration the solvent was removed using a rotary vacuum evaporator, and the freeze-dried extract stored deep freezer $\left(-80^{\circ} \mathrm{C}\right)$ until used for further analysis.

Total polyphenol content was analyzed according to the Folin-Denis method (Singleton and Rossi, 1965). After the $S$. japonica extract was prepared at a concentration of $1 \mathrm{mg} /$ $\mathrm{mL}$, Folin \& Ciocalteau's phenol reagent $60 \mu \mathrm{L}$ was added to sample solution $60 \mu \mathrm{L}$. After $3 \mathrm{~min}, 60 \mu \mathrm{L}$ of a $10 \%$ sodium carbonate $\left(\mathrm{Na}_{2} \mathrm{CO}_{3}\right)$ was added, allowed to stand at RT for $1 \mathrm{~h}$, and then, was measured at $700 \mathrm{~nm}$ using a microplate reader (Bio-Rad Inc., Hercules, CA, USA). The total polyphenol content was calculated based on a standard curve using gallic acid (Sigma Chemical Co., St. Louis, Mo. USA).

Total flavonoid content was measured according to the Nieva Moreno et al. (2000) method. After diluting the $S$. japonica extract $(100 \mu \mathrm{L})$ was mixed with $20 \mu \mathrm{L}$ of $1 \mathrm{M}$ potassium acetate and $10 \%$ aluminum nitrate adding $860 \mu \mathrm{L}$ of $80 \%$ ethanol. The absorbance was then measured at $415 \mathrm{~nm}$ after incubation for $40 \mathrm{~min}$. The total flavonoid content was calculated based on a standard curve using Quercetin (Sigma Chemical Co.).

The content of quercetin in S. japonica extract was analyzed by Yang et al. (2017) method. The S. japonica extract were dissolved in $99 \%$ methanol to prepare solutions at $10 \mathrm{mg} / \mathrm{mL}$. And then, solutions were filtered through $0.22 \mu \mathrm{m}$ filters. Using a $20 \mu \mathrm{L}$ sample loop, the sample was analyzed using a reversed-phase HPLC system (Waters 2690, MA, USA), a quaternary pump, and a vaccum degasser. Quercetin separation was performed by a prepacked ZORBAX $\mathrm{C}_{18}$ column (XDB-C $\left.\mathrm{C}_{18}, 4.6 \times 150 \mathrm{~mm}, 5 \mu \mathrm{m}\right)$. Two mobile phases were used: solvent $A, 5 \%$ acetic acid; B, 100\% acetonitrile. The gradient for HPLC analysis was linearly changed as follow (total $50 \mathrm{~min}$ ): $5 \% \mathrm{~B}$ at $0 \mathrm{~min}$, $25 \% \mathrm{~B}$ at $20 \mathrm{~min}, 100 \% \mathrm{~B}$ at $21 \mathrm{~min}, 100 \% \mathrm{~B}$ at $35 \mathrm{~min}, 5 \%$ $\mathrm{B}$ at $36 \mathrm{~min}, 5 \% \mathrm{~B}$ at $50 \mathrm{~min}$. Flow rate was set to $1.0 \mathrm{~mL}$ $/ \mathrm{min}$.

Measurement of ABTS radical scavenging activity was performed by the previously described method (Re et al., 1999). For ABTS radical formation, $14 \mathrm{mM}$ 2,2-azino-bis (3-ethylbenzthiazoline-6-sulfonic acid) (ABTS; Sigma Chemical Co.) and $4.9 \mathrm{mM}$ potassium persulfate were mixed at RT for $24 \mathrm{~h}$. It was diluted with phosphate buffered saline (PBS, $\mathrm{pH} 7.4$ ) so that the absorbance value at $732 \mathrm{~nm}$ was $0.70( \pm 0.02)$. $20 \mu \mathrm{L}$ of the sample was added to $180 \mu \mathrm{L}$ of the diluted solution, and then absorbance was measured at $732 \mathrm{~nm}$ after $1 \mathrm{~min}$

DPPH radical scavenging activity was analyzed according to the method of Blois (1958). After adding $40 \mu \mathrm{L}$ of $0.15 \mathrm{mM}$ DPPH solution to $160 \mu \mathrm{L}$ of the sample solution and stirring, the absorbance was measured at $517 \mathrm{~nm}$ after standing in the dark for $30 \mathrm{~min}$. The radical scavenging activity was calculated by the following equation.

Radical scavenging activity $(\%)=100-[($ O.D. of sample/ O.D. of control) $\times 100]$

RAW 264.7 mouse macrophage cells were purchased from Korea Cell Line Bank (KCLB). The cells were cultured in Dulbecco's Modified Eagle's Media (DMEM; Gibco, Carlsbad, CA, USA) containing 10\% (v/v) fetal bovine serum (FBS; Gibco) and 1\% penicillin-streptomycin (Gibco) 
at $37^{\circ} \mathrm{C}$ in a humidified atmosphere of $5 \% \mathrm{CO}_{2}$.

Cell toxicity of $S$. japonica extract was measured by MTT method (Jew et al., 2003). Raw 264.7 cells were seeded in a 96 well plate $\left(5 \times 10^{4}\right.$ cells $\left./ \mathrm{mL}\right)$, with various concentrations $(10,25,50,100,200 \mu \mathrm{g} / \mathrm{mL})$ of $S$. japonica extract for $24 \mathrm{~h}$. And then, followed by the addition of $0.05 \%$ MTT to each well, and the plates were further incubated for $4 \mathrm{~h}$ at $37^{\circ} \mathrm{C}$. The supernatant was removed, and $100 \mu \mathrm{L}$ DMSO was added to each well to solubilize the water-insoluble purple formazan crystals. The absorbance at $550 \mathrm{~nm}$ was measured using a microplate reader (Bio-Rad Inc.). The percentage of cell viability was estimated compared with control groups.

Measurement of nitric oxide (NO) was measured by reacting the $\mathrm{NO}_{2}^{-}$form present in the cell culture by method of Green et al. (1982). RAW 264.7 cells $\left(1 \times 10^{5}\right.$ cell $\left./ \mathrm{mL}\right)$ were seeded in 96-well plates. After incubation for $24 \mathrm{~h}$ at $37^{\circ} \mathrm{C}$, the cells were treated with $S$. japonica extract $(10,25$, $50,100 \mu \mathrm{g} / \mathrm{mL}$ ) and $100 \mathrm{ng} / \mathrm{mL}$ of lipopolysaccharide (LPS; Sigma Co.) for $24 \mathrm{~h}$. After $24 \mathrm{~h}$, the supernatants were measured for NO production using the Griess reagent (Sigma
Chemical Co.) at $540 \mathrm{~nm}$ using a microplate reader (BioRad Inc.).

The results are expressed as the mean \pm standard deviation (SD). Significance was determined by a one-way analysis of variance followed by Duncan's multiple range test using GraphPad Prism 7 (GraphPad Software Inc., San Diego, CA, USA). Statistical significance was accepted for $P$ values $<0.05$.

Changes in color and compound of S. japonica according to the different harvesting time are showed in Fig. 1. Fig. 1A shows the three color, green (May), green-red (Aug) and red (Nov) of $S$. japonica by different harvesting time. It was confirmed that the color of $S$. japonica turned red as the season changed. As a result of measuring the contents of polyphenols and flavonoids in different harvesting time of $S$. japonica, the contents in Nov harvested S. japonica were the highest at $22.81 \mathrm{mg} \mathrm{GAE} / \mathrm{g}$ and $4.56 \mathrm{mg} \mathrm{QE} / \mathrm{g}$, respectively (Fig. 1B). The contents of quercetin, the concentrations of 14.19 (May), 15.19 (Aug), and 25.45 (Nov) $\mu \mathrm{g} / \mathrm{g}$, respectively, showed the highest content in Nov harvested S. japonica,

A

\begin{tabular}{c|c|c|c}
\hline Harvesting time & May & Aug & Nov \\
\hline & & & \\
Suaeda japonica Makino & & & \\
& & & \\
\hline Color & Light green & Green-red & Red \\
\hline
\end{tabular}

B

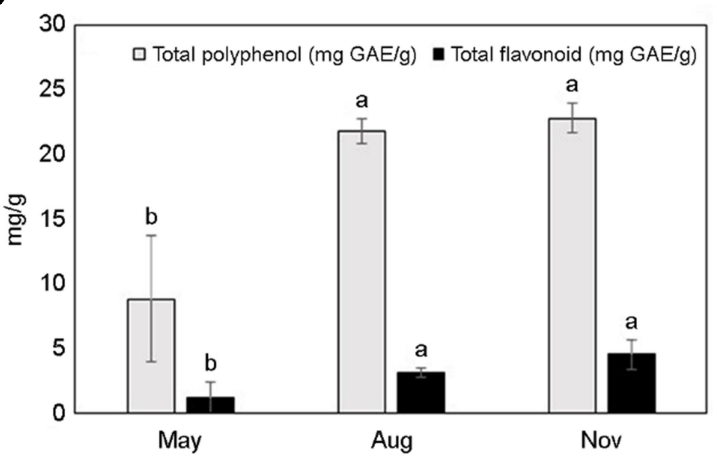

$\mathbf{C}$

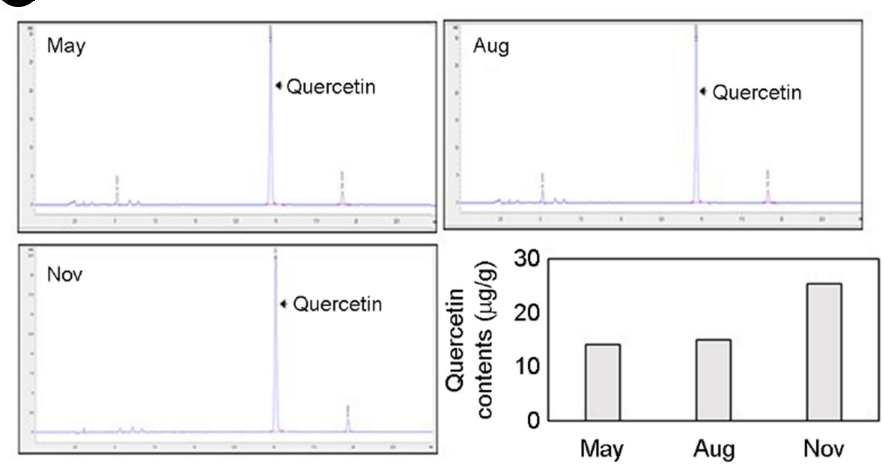

Fig. 1. The changes of color and component of $S$. japonica according to the different harvesting time. (A) three phenotypic categories of colors in S. japonica; (B) total polyphenol and flavonoid contents of S. japonica. Results are presented as the mean \pm S.D. of 3 independent in triplicate. Means with different letter on the same kind or bars are significantly different at $P<0.05$ by Duncan's multiple range test.; (C) HPLC chromatograms and contents of quercetin of S. japonica extract at different harvesting times. 
similar to the polyphenol and flavonoid results (Fig. 1C). In the study of Lee et al. (2014) showed a difference in the content of bioactive compound such as epicathechin, catechin, resveratol, and quercetin, which are polyphenol compounds, depending on the harvesting time of grapes. It was reported that this is because complex factors such as the amount of sunlight and growth period affect the content of bioactive compound. It is thought that the content of bioactive compound according to harvesting time of $S$. japonica also showed a lot of difference according to characteristics such as amount of sunlight and growth time.

To examine the antioxidant activity of $S$. japonica, ABTS and DPPH assays were conducted. ABTS is widely used to measure the antioxidant activity of natural materials, and the produced ABTS cation reacts with an antioxidant to decolorize the blue-green color, and the antioxidant activity can be evaluated by measuring its absorbance. The ABTS radical scavenging activity was the lowest in May, and the harvested in Aug and Nov showed similar effect (Fig. 2A). DPPH is a very stable free radical, and DPPH radical scavenging effect is measured by the principle of decolorizing purple compounds to yellow by the scavenging of radicals through hydrogen donation in phenolic compounds or flavonoids with hydroxy radicals (-OH) (Bondet et al., 1997). Fig. 2B shows the scavenging effect of the DPPH results of $S$. japonica by harvesting time. DPPH radical scavenging activity was showed to be $0 \%$ to $95.37 \%$ at concentrations of 50,100 , 250 and $500 \mu \mathrm{g} / \mathrm{mL}$, and it was confirmed that the activity increased in a concentration-dependent manner. At the concentration of $S$. japonica $100 \mu \mathrm{g} / \mathrm{mL}$, showed to be $12.54 \pm$ 3.24 (May), 36.75 \pm 5.32 (Aug), and 48.24 $\pm 3.12 \%$ (Nov) respectively, highest DPPH radical scavenging activity in the Nov harvested $S$. japonica. Similar to the research results of Prior et al. (1998), which reported that the antioxidant index increased in proportion to the total phenolic content, the antioxidant activity increased in proportion to the content of flavonoid, vanillic acid, a type of phenolic compound. It was thought to be due to the difference in the content of

A

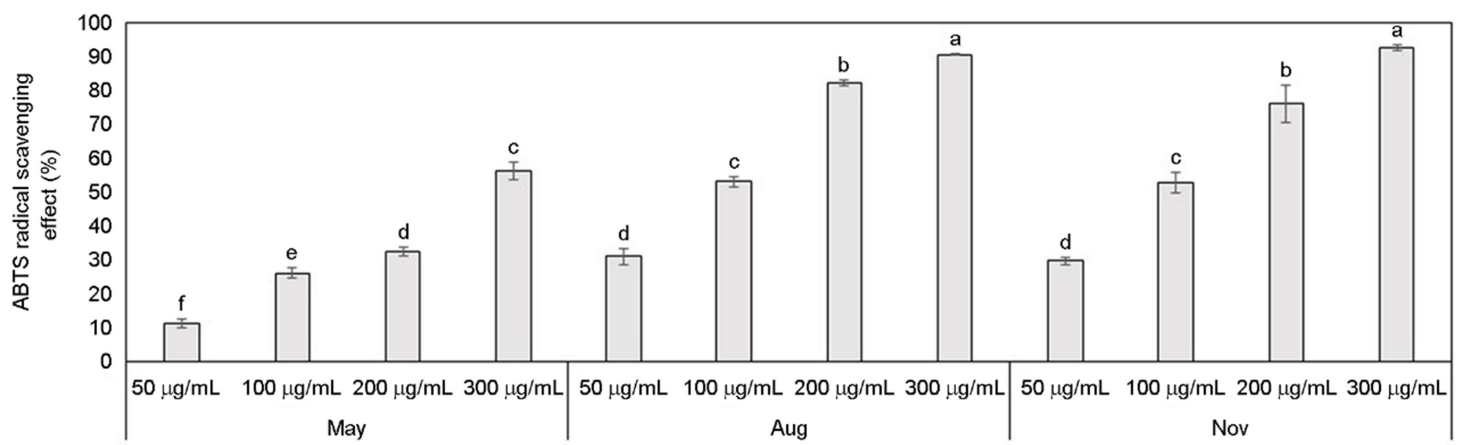

B

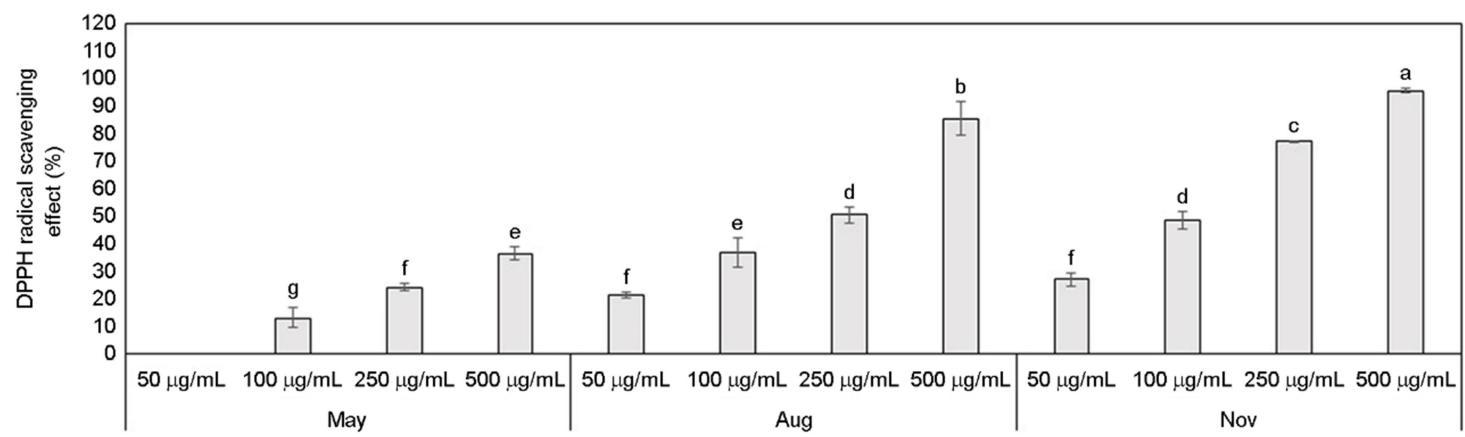

Fig. 2. Comparison of ABTS and DPPH radical scavenging activity of $S$. japonica according to the different harvesting time. Results are presented as the mean \pm S.D. of 3 independent in triplicate. Means with different letter on the same kind or bars are significantly different at $P<0.05$ by Duncan's multiple range test. 
A

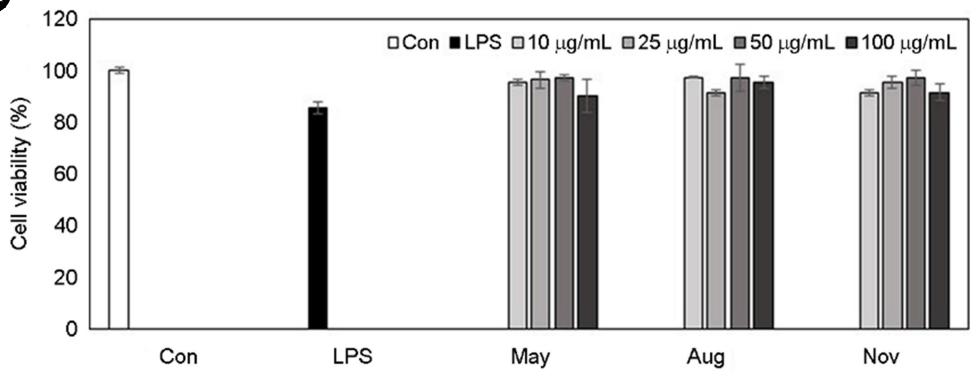

B

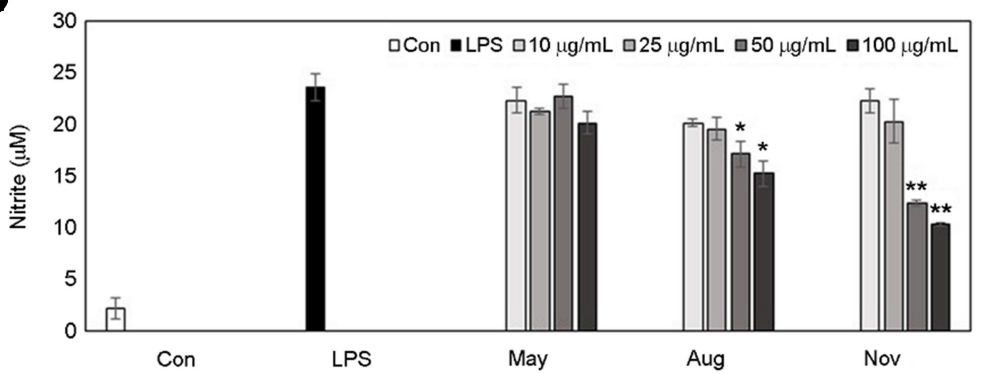

Fig. 3. Effect of $S$. japonica according to the different harvesting time on cell viability and NO inhibition effect. (A) Cell viability was measured by MTT assay. RAW 264.7 cells were incubated in medium with $S$. japonica at different harvesting times and LPS. After $24 \mathrm{~h}$, MTT reagent was added to the medium. After $4 \mathrm{~h}$ of incubation, the absorbance was read at $550 \mathrm{~nm}$; B, Inhibitory effect of $S$. japonica at different harvesting times on the production of $\mathrm{NO}$ on LPS-induced inflammation in RAW 264.7 cell. Results are presented as the mean \pm S.D. of 3 independent in triplicate. $* P<0.05$, compared to LPS group. ${ }^{* *} P<0.01$, compared to LPS group. phenolic compounds in $S$. japonica by different harvesting time.

In order to evaluate of S. japonica extract on cytotoxicity by harvesting time, RAW 264.7 cells were treated by various concentration of $S$. japonica extract, and the survival rate of the cells was evaluated through the MTT assay (Fig. 3A). The $S$. japonica extracts by different harvesting time did not show cytotoxicity when treated with concentrations of $10,25,50,100 \mu \mathrm{g} / \mathrm{mL}$. Therefore, $S$. japonica extracts by different harvesting time were NO inhibition effect tested at concentrations that did not affect cytotoxicity.

Macrophage cells play an important role in the inflammatory response (Iontcheva et al., 2004), and active nitrogen species (RNS) such as $\mathrm{NO}, \mathrm{HNO}_{2}$, and ONOO. are produced in large quantities due to the immune response of macrophages, neutrophils and other immune cells during the inflammatory reaction (Delanty and Dichter, 1998). Nitric oxide (NO), which is known to play an important role in the induction of inflammation in recent years as a kind of active oxygen, is produced from L-arginine by NOS (Nitric oxide synthase) (Weisz et al., 1996). In particular, iNOS (inducible NOS) is involved in the inflammatory response, and is expressed when inflammatory cytokines such as TNF$\alpha$ and LPS are stimulated (Moncada et al., 1991). Fig. 3B shows the results of measuring the effect of the $S$. japonica extracts by different harvesting time on NO production in RAW 264.7 cells using LPS, which is used as an inflammatory inducer. In the control group in which only RAW 264.7 cells were cultured, the concentration of NO was measured to be $2.12 \mu \mathrm{M}$, but in the group treated with LPS, the concentration of NO was increased to $23.56 \mu \mathrm{M}$. In the experimental group treated with the $S$. japonica extract, the NO concentration was decreased from $50 \mu \mathrm{g} / \mathrm{mL}$ of the $S$. japonica extract harvested in Aug and Nov. The NO inhibitory effect was 12.34 and $10.32 \mu \mathrm{M}$ respectively at the concentration of 50 and $100 \mu \mathrm{g} / \mathrm{mL}$ of the $S$. japonica extract harvested in Nov. It was confirmed that the most excellent.

Overall, it was confirmed that the extract of S. japonica extract showed antioxidant activity and anti-inflammatory activity, and especially, all of S. japonica in harvested Nov showed high bioactivity. it is thought to be due to the fact that the antioxidant and anti-inflammatory active ingredients in S. japonica change depending on the harvesting time. Therefore, when S. japonica is used as an antioxidant and anti-inflammatory functional raw material, it is thought that it should be harvested at the time of highest activity. 


\section{ACKNOWLEDGEMENT}

This research was supported by the Ministry of Trade, Industry \& Energy (MOTIE), Korea Institute for Advancement of Technology (KIAT) through the Encouragement Program for The Industries of Economic Cooperation Region (Project Name: Commercialized and development of functional raw materials for wellness anti-aging based fermentation techniques by Jeju' regional specilities: P0007266).

\section{CONFLICT OF INTEREST}

The authors declare that there is no conflict of interests regarding the publication this articles.

\section{REFERENCES}

Bayr H. Reactive oxygen species. Critical Care Medicine. 2005. 33: 498-501.

Blois MS. Antioxidant activity determination by the use of a stable free radical. Nature. 1958. 181: 1199-1200.

Bondet V, Brand-Williams W, Berset C. Kinetics and mechanisms of antioxidant activity using the DPPH. free radical method. LWT-Food Science and Technology. 1997. 30: 609-615.

Choi J, Kim YJ, Kim JH, Song BS, Yoon YH, Byun MW, Kwon JH, Chun SS, Lee JW. Antioxidant activities of the extract fractions from Suaeda japonica. Journal of the Korean Society of Food Science and Nutrition. 2009. 38: 131-135.

Delanty N, Dichter MA. Oxidative injury in the nervous system. Acta Neurologica Scandinavica. 1998. 98: 145-153.

Green LC, Wagner DA, Glogowski J. Analysis of nitrate, and [15N] nitrate in biological fluids. Analytical Biochemistry. 1982. 126: 131-138.

Greenway H, Munns R. Mechanisms of salt tolerance in nonhalophytes. Annual Review of Plant Physiology. 1980. 31: 149-190.

Han SK, Kim SM, Pyo BS. Antioxidative effect of glasswort (Salocornia herbacea L.) on the lipid oxidation of pork. Korean Journal for Food Science of Animal Resources. 2003. 23: 46-49.

Iontcheva I, Amar S, Zawawi KH, Kantarci A, Van Dyke TE. Role for moesin in lipopolysaccharide-stimulated signal transduction. Infection and Immunity. 2004. 72: 2312-2320.

Ito N, Fukushima S, Haqlwara A, Shibata M, Ogiso T. Carcinogenicity of butylated hydroxyanisole in $\mathrm{f} 344$ rats. Journal of the National Cancer Institute. 1983.70: 343-352.

Jew SS, Bae ON, Chung JH. Anti-inflammatory effects of asiatico- side on inducible nitric oxide synthase and cyclooxygenase-2 in Raw-264.7 cell line. Journal of Toxicology and Public Health. 2003. 19: 33-37.

Jung BM, Park JA, Bae SJ. Growth inhibitory and quinone reductase induction activities of Salicornia herbaecea $\mathrm{L}$. fractions on human cancer cell lines in vitro. Journal of the Korean Society of Food Science and Nutrition. 2008. 37: 148-153.

Kahl R, Kappus H. Toxicology of the synthetic antioxidants bha and bht in comparison with the natural antioxidant vitamine. Zeitschrift fur Lebensmittel-untersuchung Und-forschung. 1993. 196: 329-338.

Larcher W. Physiological plant ecology - Ecophysiological and stress physiology of functional groups. 3rd ed. Springer, Berlin, Germany. 1995.

Lee SK, Kim SK, Hong EY, Chun SH, Son IC, Kim DI. Effect of Harvest Time on the Several Phenolic Compounds and Fruit Quality of Grape Cultivars. Korean Journal of Plant Resources. 2014. 27: 119-124.

Lee SO, Lee HJ, Yu MH, Im HG, Lee IS. Total polyphenol contents and antioxidant activities of methanol extracts from vegetables produced in Ullung island. Korean Journal of Food Science and Technology. 2005. 37: 233-240.

Moncada S, Palmer RM, Higgs EA. Nitric oxide: physiology. Pathophysiology, and pharmacology. Pharmacological Reviews. 1991. 43: 109-142.

Nieva Moreno MI, Isla MI, Sampietro AR, Vattuone MA. Comparison of the free radical-scavenging activity of propolis from several regions of Argentina. Journal of Ethnopharmacology. 2000. 71: 109-114.

Prior RL, Cao G, Martin A, Sofic E, McEwen J, O'Brien C, Mainland CM. Antioxidant Capacity as Influenced by Total Phenolic and Anthocyanin Content, Maturity, and Variety of Vaccinium Species. Journal of Agricultural and Food Chemistry. 1998. 46: 2686-2693.

Re R, Pellegrini N, Proteggente A, Pannala A, Yang M, Rice-Evans C. Antioxidant activity applying an improved ABTS radical cation decolorization assay. Free Radical Biology and Medicine. 1999. 26: 1231-1237.

Singleton VL, Rossi JA. A colorimetry of total phenolics with phosphomolybdic-phosphotungstic acid reagents. American Journal of Enology and Viticulture. 1965. 16: 144-158.

Weisz A, Ciatiello L, Esumi H. Regulation of the mouse inducibletype nitric oxide synthase gene promoter by interferon-gamma, bacterial lipopolysaccharide and NGmonomethyl-L-arginine. 
Biochemical Journal. 1996. 316: 209-215.

Yang HM, Sun CY, Liang JL, Xu LQ, Zhang ZB, Luo DD, Chen HB, Huang YZ, Wang Q, Lee David YW, Yuan J, Li YC. Supercritical-Carbon dioxide fluid extract from Chrysanthemum indicum enhances anti-tumor effect and reduces toxicity of bleomycin in tumor-bearing mice. International Journal of Molecular Sciences. 2017. 18: 465-479.
https://doi.org/10.15616/BSL.2020.26.4.376

Cite this article as: Choi JH, Lee SG, Kang H. Changes in the Compound and Bioactivity of Suaeda japonica Makino Extract by Different Harvesting Time. Biomedical Science Letters. 2020. 26: 376-382. 